\title{
Die Clemente
}

\section{Der \\ 3oadbimifdoen שonftitution vom Tabre 152\%.}

Fin B̧eitrag

our

$\mathbb{E} \mathfrak{e}$ twickelungsgefoldichte

bes

Deutfonen Siechts

non

\section{Dr. fudwig Givard fogdenanu,}

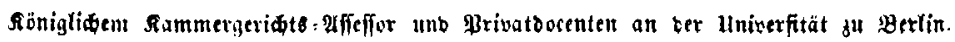

$$
\text { P3 } \mathfrak{x} \text { I } \mathrm{i} \text { t. }
$$

Berlag von Beit und Eomp.

$18+1$. 
Erst in unserer zeit, naclutem las studium les romischen rechls all sejne alle reinheil unl strenge zurückgefïlıt, das des einheimischen wieder zu vollen ehren gebracht worten ist, darf man eine langsam lueraurūckente reformation unserer rechtsverfassung hoften unı voraussehen. Eine hatptrolle zugetacht ist aber hierbei der geschichte les dellschen rechts in ilurem weilesten umfang.

Jac. Grimm. 
Rönigl. Geb. Regations = und Geb. Ober: Tribumals: Tathe 2c, 2c, Mitter 2c, 2c.

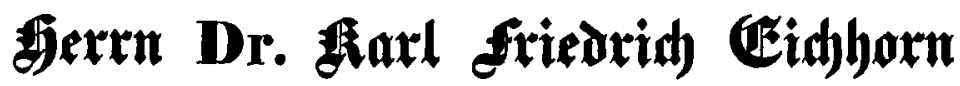

ebrerbietig jugecignet. 
